Surveyor

\title{
Errors in Timepieces of Precision
}

\section{E.P. Cotton}

To cite this article: E.P. Cotton (1919) Errors in Timepieces of Precision, Surveyor, 32:1, 10-16, DOI: $10.1080 / 18324460.1919 .10439451$

To link to this article: http://dx.doi.org/10.1080/18324460.1919.10439451

曲 Published online: 01 Aug 2012.

Submit your article to this journal

Џll Article views: 2

Q View related articles $\sqsubset$ 


\section{Errors in Timepieces of Precision.}

During my administration of the Lands and Surveys of Nigeria, it became the duty of the Survey Department to direct a small but fairly well-equipped observatory, which was used almost entirely for obtaining time-chiefly for the purpose of adjusting and determining the rate and irregularity of a considerable number of chronometers and chronometer-watches, which were constantly needed for expeditions on which longitude was very frequently determined.

Our timepieces consisted of two first-class astronomical clocks, five or six chronometers, and about the same number of chronometerwatches. These were in charge of Mr. A. Cleminson, late of Queensland Survey Department, who is a very excellent observer.

It was only during his leave of absence (six months each year) that it became my duty to take over the observatory.

It was during one of these periods that I set myself the task of determining very accurately the irregularity and mean rate of these timepieces. On my return to Europe I compared my results with those obtained at observatories in England and on the Continent.

I had intended to give the results of my investigations, but perhaps it would be shorter, and more useful to those engaged on similar work, to publish the investigations of that observatory, which I consider to be the most accurate and complete.

I propose, therefore, to translate freely from the proceedings of the world-famed French University of Besançon, adding only the results of my own investigations where they appear to be of some special value.

Let us now consider some of the principal errors in timepieces of precision.

The clock is not a perfect instrument, and its rate is only regular within certain limits. If, for example, a clock has gained one second in ten days, its mean rate is $+\frac{1}{i \sigma}$ second per day ; but in comparing it each day with accurately obtained time, it will be found to oscillate around $+T_{i}^{\frac{1}{6}}$ second; the difference between the true and the mean rate is termed the irregularity (l'écart de marche).

The irregularities vary naturally with the class of clock, the stability of its support, etc. With fairly good clocks and chronometers the irregularity may reach $\frac{1}{2}$ second and even I second, per day; while with good observatory clocks this error should be of the order of is second per day.

It is difficult to obtain the absolute time to a greater refinement than $\frac{1}{10}$ second; but the lapse of a short interval of time may be obtained with much greater accuracy.

Suppose for the moment that we knew how to read a clock with an infinite precision, and that this clock had an irregularity of 0.3 second per day, what would be the uncertainty in the measure of an interval of the order of $\mathrm{I}$ second? In such cases some people will 
not hesitate to reason thus:- Since the error is $\frac{3}{10}$ second per day or per 86,400 seconds, for I second it will be 86,400 less, that is to say of the order of $\bar{i} \overline{0} \frac{\mathbf{s}}{\mathrm{O}} \overline{\mathrm{o}} \overline{\mathrm{o}}$ of a second. Such reasoning is, of course, false ; the error certainly is very much greater ; this follows immediately from the theory of probabilities.

Let us suppose that we could measure exactly in seconds and fractions of seconds the duration of an oscillation of the pendulum of the clock. We would find that all the oscillations were not of the same duration; this proves the existence of accidental perturbations, acting sometimes in one way and sometimes in another (we will admit for the moment that there are not any systematic perturbations arising, for example, from slow variations of temperature and barometric pressure).

The mean of all the values thus found for a large number of oscillations will give the duration of mean oscillation; and we can thus deduce the mean error by its difference from one complete oscillation. The errors between the duration of one oscillation and the mean will be sometimes positive and sometimes negative, and their algebraic sum will be zero.

What we are trying to ascertain is the irregularity, or the errors positive or negative the most probable, or, at least, the order of their magnitude. We generally calculate the mean error by simply taking the mean of all the errors, neglecting their sign. This mean error differs a little from the most probable error, because the large errors are less frequent than the small; but as we propose to calculate the order of the size of the uncertainty, the difference is of no practicable value.

If, for example, we find the mean error to be of a value $e$, this is equivalent to saying that the value of an oscillation can only be obtained to the order of $\pm e$; the real error can, of course, be more, or less, and can reach $2 e$ or $3 e$, and even, but very rarely, $4 e$ or $5 e$.

Having established this, let us suppose that we have determined a large number of times the duration of $\mathbf{2} 2$ successive oscillations. We would find; as already stated, a series of different values, of which the mean would give us the mean error ; let it be $E^{\prime}, E^{\prime \prime}, E^{\prime \prime \prime}$, etc., these being the errors, positive or negative, between each value and the mean value.

Let this be the same in each series of 12 oscillations, $e_{1}, e_{2}, e_{3} \ldots$ $e_{12}$, being the errors between the duration of each oscillation and the duration of the mean oscillation.

It is evident that, for each series, the total error is equal to the algebraic sum of the errors $e$, taken with regard to their sign.

$$
\begin{aligned}
& E^{\prime}=e_{1}^{\prime}+e_{2}^{\prime}+e^{\prime}{ }_{3}+\ldots e^{\prime}{ }_{12} \\
& E^{\prime \prime}=e^{\prime \prime}{ }_{1}+e^{\prime \prime}{ }_{2}+e^{\prime \prime}{ }_{3}+\ldots e^{\prime \prime}{ }_{12} \\
& E^{\prime \prime \prime}=e^{\prime \prime \prime}{ }_{1}+e^{\prime \prime \prime}{ }_{2}+e^{\prime \prime \prime}{ }_{3}+\ldots e^{\prime \prime \prime}{ }_{12} \text { etc. }
\end{aligned}
$$

It is clear that $E^{\prime}, E^{\prime \prime}, E,{ }^{\prime \prime \prime}$ etc., is smaller than 12 times the mean error $e$, for $e_{1}^{\prime} e^{\prime}{ }_{2}, e^{\prime}{ }_{3} \ldots e_{12}^{\prime}$ are, as a mean, equal to $e$, and 
are sometimes positive and sometimes negative; but the sum of the positive errors do not exactly counterbalance the negative errors, and thus $E^{\prime}, E^{\prime \prime}, E^{\prime \prime \prime}$. . . etc., are not zero; they are moreover greater than $e$.

The theory of probabilities shows that the mean of the errors $E^{\prime}, E^{\prime \prime}, E^{\prime \prime \prime}$... etc. (the mean error of 12 oscillations) is equal to the mean error $e$ for one oscillation multiplied by the square root of the number of oscillations $(\sqrt{12})$; thus the duration of 4 oscillations has an uncertainty twice as great as one oscillation. In the same way the uncertainty of 86,400 oscillations is $\sqrt{\mathbf{8 6 , 4 0 0}}$, say about 300 times greater than in one oscillation.

If the mean daily irregularity is of the order of 0.3 second, the uncertainty of the duration of one oscillation (one second) will thus be 300 times less, say $\frac{0.3}{300}$ second, and not $\frac{0.3}{86,400}$.

Thus, in spite of the refinements in reading, there exists an uncertainty of :-

$$
\begin{aligned}
& \frac{I}{1000} \text { second in the duration of one second, } \\
& \frac{I}{100} \text { second in the duration of one I00 seconds, } \\
& \frac{I}{I O} \text { second in the duration of one I0,000 seconds, }
\end{aligned}
$$

and for 24 hours 0.3 second. For Io days the uncertainty will be of the order of one second.

The real irregularity, however, can easily reach several seconds, or be very much less, for the chances of this error being superior or inferior to the mean irregularity are almost equal. With a clock whose daily mean irregularity does not exceed 0.05 second per day we may have an uncertainty of about $\frac{1}{6}$ of that amount (this applies to first-class observatory clocks).

It is extremely difficult to determine the daily mean error. Careful attention is necessary to systematic variations which may produce a slow variation on the rate, so that we cannot depend on even a large number of observations as a true evidence of the mean error. It is, however, possible to obtain a much more refined result by employing the graphic method. As an illustration, I will give the actual results of two clocks at Besançon observatory. 
Feb. 28, I9I9.

\begin{tabular}{|c|c|c|c|c|c|c|c|c|c|c|}
\hline \multicolumn{2}{|c|}{$\begin{array}{c}1 \\
\text { Days. } \\
1913 .\end{array}$} & \multicolumn{3}{|c|}{$\begin{array}{c}2 \\
\text { Mean Time } \\
\text { determined by } \\
\text { Sidereal Clock. }\end{array}$} & \multicolumn{3}{|c|}{$\begin{array}{c}3 \\
\text { Mean Time } \\
\text { indicated by } \\
\text { Mean Time Clock. }\end{array}$} & \multicolumn{2}{|c|}{$\begin{array}{c}4 \\
\text { Difference } \\
3-2\end{array}$} & \multirow[t]{2}{*}{$\begin{array}{c}5 \\
\text { Rates } \\
\text { Algebraic. } \\
\text { Sum of the } \\
\text { daily varia } \\
\text { tions of the } \\
\text { two Clocks }\end{array}$} \\
\hline Sept. & I & & $\begin{array}{c}\text { M. } \\
\text { I3 }\end{array}$ & $\begin{array}{l}\text { S. } \\
54.25\end{array}$ & $\begin{array}{c}\mathrm{H} . \\
20\end{array}$ & $\begin{array}{l}\text { M. } \\
\text { I5 }\end{array}$ & $\begin{array}{l}\text { S. } \\
5.00\end{array}$ & & $\begin{array}{c}\text { S. } \\
\text { I0. } 75\end{array}$ & \\
\hline & 2 & & 20 & 46.57 & & $2 \mathrm{I}$ & 58.00 & I & II. 43 & 0.68 \\
\hline & 3 & & I4 & 55.97 & & I6 & 8.00 & $\mathbf{I}$ & $\mathrm{r} 2.03$ & 0.60 \\
\hline & 4 & & 22 & 08.25 & & 23 & I6.00 & I & I 2.75 & 0.72 \\
\hline & 5 & & 23 & 6.52 & & 24 & 20.00 & I & $13.4^{8}$ & 0.73 \\
\hline & 6 & & II & $2 I .9 I$ & & 12 & 36.00 & I & $\mathbf{1} 4.09$ & $0.6 \mathrm{I}$ \\
\hline & 7 & & 43 & 25.09 & & 44 & 40.00 & I & $\mathrm{I} 4.9 \mathrm{I}$ & 0.82 \\
\hline & 8 & & 18 & 57.54 & & 20 & I3.00 & I & I $5.4^{6}$ & 0.55 \\
\hline & 9 & & I3 & II.94 & & I4 & 28.00 & I & r6.06 & 0.60 \\
\hline & IO & & 20 & $I_{4} .22$ & & 21 & 31.00 & $\mathbf{I}$ & I $6.7^{8}$ & 0.72 \\
\hline & II & & I4 & $3^{8} .59$ & & 15 & 56.00 & $I$ & $17.4 I$ & 0.63 \\
\hline & 12 & & I5 & 31.89 & & 16 & 50.00 & I & I8. II & 0.70 \\
\hline & I3 & 20 & 9 & 46.28 & 20 & II & 5.00 & I & I 8.72 & $0.6 \mathrm{I}$ \\
\hline & I. & I9 & 58 & II.63 & I9 & 59 & 3I.00 & I & I9.37 & 0.65 \\
\hline & 15 & 20 & II & 02.96 & & I2 & 23.00 & $I$ & 20.04 & 0.67 \\
\hline & 16 & & 4 & 52.43 & & 6 & I 3.00 & I & 20.57 & 0.53 \\
\hline & 17 & & 23 & I2.86 & & 24 & 34.00 & I & $2 \pi .14$ & 0.57 \\
\hline & I8 & & 23 & 56.18 & & 25 & 18.00 & I & 21.82 & 0.68 \\
\hline & I9 & & 5 & 52.60 & & 7 & 15.00 & I & $22.4^{\circ}$ & $0.5^{8}$ \\
\hline & 20 & & I8 & 33.97 & & I9 & 57.00 & I & 23.03 & 0.63 \\
\hline & $2 I$ & & 32 & 0.20 & & 33 & 24.00 & I & 23.80 & 0.77 \\
\hline & 22 & & I9 & 20.73 & & 20 & 45.00 & I & 24.27 & 0.47 \\
\hline & 23 & & I9 & 49.09 & & $2 \mathrm{I}$ & I 4.00 & I & $24.9 \mathrm{I}$ & 0.64 \\
\hline & 24 & & 26 & 3 I. 44 & & 27 & 57.00 & I & 25.56 & 0.65 \\
\hline & 25 & & $I_{4}$ & 36.90 & & 16 & 3.00 & I & 26.10 & 0.54 \\
\hline & 26 & & I9 & 59.40 & & $2 I$ & 26.00 & $\mathbf{I}$ & 26.60 & $0.5^{\circ}$ \\
\hline & 27 & & $\mathrm{r} 4$ & 3.82 & & I5 & 31.00 & I & 27.18 & $0.5^{8}$ \\
\hline & 28 & I9 & 49 & 41.28 & I9 & $5 I$ & 9.00 & $I$ & 27.72 & 0.54 \\
\hline & 29 & 20 & 32 & 2.76 & & 33 & 31.00 & I & 28.24 & 0.52 \\
\hline & 30 & & 32 & 6.20 & & 33 & 35.00 & $I$ & 28.80 & 0.56 \\
\hline Oct. & I & & I9 & $5 \mathrm{I} .75$ & & $2 I$ & 21.00 & $I$ & 29.25 & 0.45 \\
\hline & 2 & & 23 & 34.49 & & 25 & 4.00 & $I$ & $29.5 \mathrm{I}$ & 0.26 \\
\hline & 3 & & 20 & 48.40 & & 22 & r8.00 & $I$ & 29.60 & 0.09 \\
\hline & 4 & & 30 & $5 \cdot 3 I$ & & $3 I$ & 35.00 & $I$ & 29.69 & 0.09 \\
\hline & 5 & & 46 & 6.13 & & 47 & 36.00 & I & 29.87 & o.I8 \\
\hline & 6 & & I9 & 8.93 & & 20 & 39.00 & I & 30.07 & 0.20 \\
\hline & 7 & & IO & 38.84 & & I2 & 9.00 & $I$ & 30.16 & 0.09 \\
\hline & 8 & & 32 & 48.65 & & 34 & 19.00 & I & 30.35 & 0.19 \\
\hline & 9 & & 12 & $5.5^{\circ}$ & & 13 & 36.00 & $I$ & 30.50 & 0.15 \\
\hline & IO & & 22 & $2.3 I$ & & 23 & 33.00 & I & 30.69 & 0.19 \\
\hline & II & & I9 & 36.17 & & $2 \mathrm{I}$ & 7.00 & $I$ & 30.83 & O.I4 \\
\hline & I2 & & 35 & 7.06 & & 36 & $3^{8} .00$ & I & 30.94 & o.II \\
\hline & I3 & & 20 & 57.83 & & 22 & 29.00 & $I$ & 3I.I7 & 0.23 \\
\hline & I4 & & 23 & 55.78 & & 25 & 27.00 & I & 31.22 & 0.05 \\
\hline & I5 & & I5 & 0.70 & & 16 & 32.00 & I & 31.30 & 0.08 \\
\hline
\end{tabular}




\section{FIG. I}

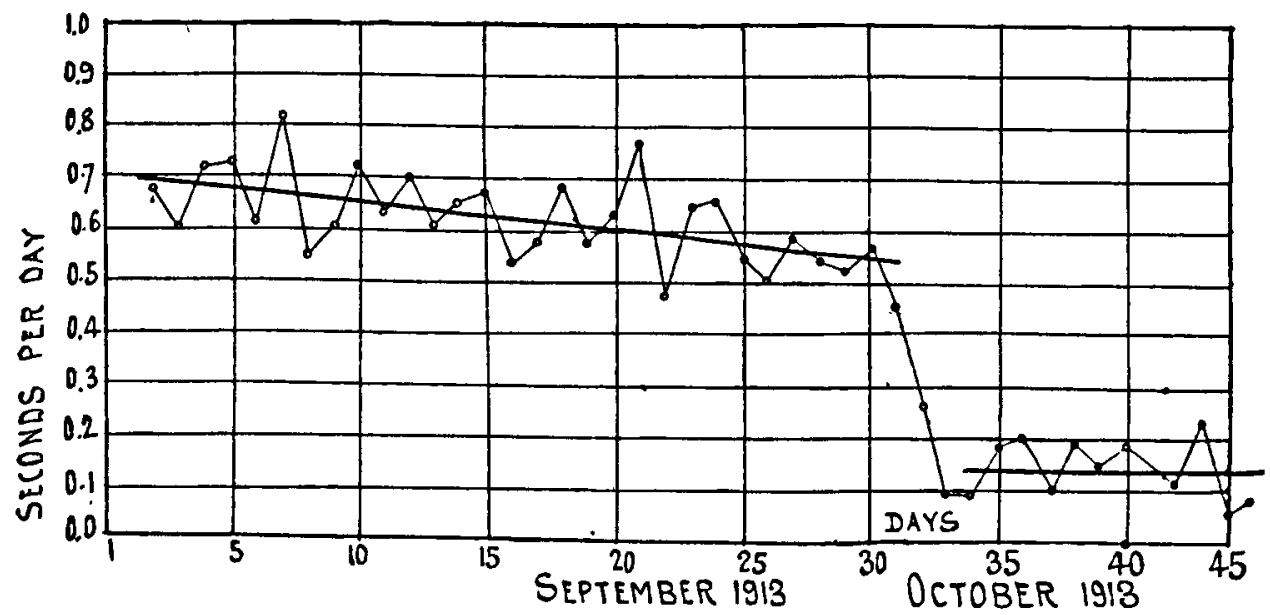

One of these clocks is a sidereal clock, the other a mean time clack ; this latter retards with respect to the sidereal clock by a quantity which should be constant, but this retardation is not constant on account of errors in both clocks.

The daily rate of the mean time clock with respect to the sidereal clock is shown graphically (Fig. I.), and is represented by the points. The heavy line evidently represents the mean rate, which we see can vary slowly and even abruptly.

The mean of the errors between each point and the heavy line permits us to calculate the total mean error, which is evidently the mean error of the two clocks-this sum is 0.05 second. But it is necessary to point out that these two clocks, placed side by side, may be acted upon by identical perturbations which do not modify their difference of rate; therefore we can admit that the daily mean errors of these two clocks are of the order of $\frac{1}{2} \sigma$ second.

With these clocks, however, which are very excellent, the mean uncertainity may reach 0.15 second in 9 days. This mean may be augmented by faults of thermic compensations, by the non-uniformity of temperature in a vertical direction, barometric pressure, etc.

It is not rare to have an error of several tenths of a second, but it may be seen on the graph (Fig. I.) that there are errors amounting four times that of the mean irregularity. If such irregularities had continued, the error might have amounted to io second or $\frac{8}{10}$ second, but this rarely happens.

Perhaps some of those who are not familiar with this class of investigation may find a difficulty in deriving the mean irregularity from the table of comparisons of the two clocks or from the graph. I shall therefore give a simple concrete example taken from a good 
chronometer:--Let $\phi=$ mean irregularity, $M_{1}=$ mean rate, and $m_{1}, m_{2} \quad \ldots \quad \ldots \quad$ etc. $=$ daily rates.

$$
\begin{aligned}
& \text { Seconds. Seconds. } \\
& m_{1}-M_{1}=-0.8+0.60=-0.20 \\
& m_{2}-M_{1}=-0.6+0.60=0.00 \\
& m_{3}-M_{1}=-0.6+0.60=0.00 \\
& m_{4}-M_{1}=-0.5+0.60=+0.10 \\
& m_{3}-M_{1}-0.5+0.60=+\frac{0.10}{5 \longdiv { 0 . 4 0 }}=0.08 \text { seconds }
\end{aligned}
$$

Therefore $\varphi=0.08$ seconds $=$ mean irregularity for five days.

It will be seen that No. 3 I on the graph has been discarded, the error being too great to be admissible. There are several criteria for this class of error, of which Wright's is, perhaps, the most popular. With frequent use, they can be applied empirically.

The variation of clocks has greatly complicated the conservation of accurate time.

In order to diminish this uncertainty, several clocks or chronometers are employed, and the mean of their corrected and weighted rates are taken. This diminishes the error, but not to the extent that is generally expected.

Suppose, for example, we take the sum of the indications of our $N$ clocks or chronometers, the jrobable uncertainty will be (as with the I2 oscillations already considered) equal to $\sqrt{N}$, the probable uncertainty of the elements of the sum.

In order to arrive at a mean of these indications, we divide by $N$; the uncertainty of the mean will thus be $N$ times smaller. and will be equal to $E \frac{\sqrt{N}}{N}$, say $\frac{E}{\sqrt{N}}$; the uncertainty of the mean is then $\sqrt{N}$ times smaller than the uncertainty of the indication of one of these clocks.

We have already seen that an error $\frac{1}{2}$ second is not rare in ro or I2 days; to reach a certainty of tio second it would be, therefore, necessary to have at least Ioo clocks (the mean error would then be divided by I0).

With a good marine chronometer, of which the daily mean error is of the order of 0.3 second, the mean uncertainty is in ro days of the order of one second. With Io chronometers it will be reduced to 0.3 second in the same time.

Instead of augmenting the number of clocks, the idea at present is to improve them, and to place them in inclosures at a constant temperature.

In Europe, and especially on the Continent where there are a large number of well-equipped observatories, a properly instituted interchange of times has been established, which has greatly diminished the days without observations for time, etc., for it is highly improbable that cloudy nights should occur simultaneously at all these observatories. As these comparisons can be made to a refinement of to second, it is evident that the probable error arising therefrom is negligible in comparison with that of obtaining absolute time. 
It is very desirable that all the observatories keep the same time as exactly as possible, in order to class the meteorologic phenomena to note accurately the occurrence of earthquakes and to study their propagation, etc. In this case we measure rather the duration than determine the absolute time, and we can arrive at a greater precision if the clocks are in accord.

$$
\text { E. P. COTTON, }
$$

Late Commissioner of I.ands and Director of Surveys, Nigeria.

\title{
Pioneer Surveyors of New South Wales.
}

\author{
By John WeINGarth, L.S. \\ GEORGE WILLIAM EVANS \\ (Continued).
}

The following is tak.n from the Historical Records referring to the Journal of Assistant Surveyor Evans. :-

" G. W. Evans and his party of four men left Bathurst on the I3th of May, 1815, and encamped in the evening in the neighbourhood of Perth.* One day was lost in searching for the horses which had strayed, and on the x6th he reached the centre of three peaks now known as the Three Brother. Evans named these hills, Antill's Peak, Mount Macquarie, and Maclaine's Peak.

"On the 22nd, he discovered and named Mount Lachlan, about three miles south east of Carcoar. He camped four miles south of this peak; and on the following day he travelled west for four miles, when in the distance he sighted the Canobolas, and named the peak Jamison's Table Mountain. On the $2 \psi^{\text {th }}$, he discovered Limestone Creek at a point a little north of west from Lyndhurst. He followed the creek down to its junction with the Belabula river, which he named Lewis' Creek. On the 25th, he ascended the Sugarioaf, which he named Mount Lewin. On the 26th, he passed Licking Hole Creek, and on the following day he discovered the Lachlan River between North Logan and Cowra. On Sunday, the 28th, he allowed three of his men to rest in camp, and with the fourth man he ascended the River for six miles to the neighbourhood of Cowra, and named the river flats Oxley's Plains. During the next four days, he traced the river down to its junction with Mlandagery Creek, which he named Byrne's Creek.

"From this point, he was compelled to commence his return journey on the and of June, I8I5, and he arrived at Bathurst ten days later."

\footnotetext{
* Now Perthville.
} 